\title{
Flight plan for the future: floatplane pilots and researchers team up to predict invasive species dispersal in Alaska
}

\author{
Tobias Schwoerer (1) - Roman J. Dial (1) - Joseph M. Little ( Aaron E. Martin • \\ John M. Morton • Jennifer I. Schmidt 1 - Eric J. Ward $(\mathbb{D}$
}

Received: 14 June 2021 / Accepted: 6 December 2021/Published online: 9 January 2022

(C) The Author(s) 2021

\begin{abstract}
Aircraft can transport aquatic invasive species (AIS) from urban sources to remote waterbodies, yet little is known about this long-distance pathway. In North America and especially Alaska, aircraft with landing gear for water called floatplanes are used for recreation access to remote, often roadless wilderness destinations. Human-mediated dispersal of AIS is particularly concerning for the conservation of pristine wildlands, yet resource managers are often challenged by limited monitoring and response
\end{abstract}

Supplementary Information The online version contains supplementary material available at https://doi.org/10.1007/ s10530-021-02712-3

T. Schwoerer $(\bowtie) \cdot$ J. M. Little

International Arctic Research Center, University of Alaska Fairbanks, 2160 N Koyukuk Drive, Fairbanks, AK 99775, USA

e-mail: tschwoerer@alaska.edu

R. J. Dial

Alaska Pacific University, 4101 University Dr,

Anchorage, AK 99508, USA

J. M. Little

Franke College of Business, Northern Arizona University, 101 E McConnell Dr, Flagstaff, AZ 86011, USA

A. E. Martin

U.S. Fish and Wildlife Service, 1011 E. Tudor Rd,

Anchorage, AK 99503, USA capacity given the vast areas they manage. We collected pathway data through a survey with floatplane pilots and used a Bayesian hierarchical model to inform early detection in a data-limited situation. The study was motivated by Alaska's first known AIS, Elodea spp. (Elodea) and its floatplane-related dispersal. For 682 identified floatplane destinations, a Bayesian hierarchical model predicts the chance of flights originating from AIS source locations in freshwater and estimates the expected number of flights from these sources. Model predictions show the potential for broad spread across remote regions currently not known to have Elodea and informed

\author{
J. M. Morton \\ Alaska Wildlife Alliance, P.O. Box 202022, Anchorage, \\ AK 99520, USA \\ J. I. Schmidt \\ Institute of Social and Economic Research, University of \\ Alaska Anchorage, 3211 Providence Dr, Anchorage, \\ AK 99508, USA \\ E. J. Ward \\ Conservation Biology Division, Northwest Fisheries \\ Science Center, National Marine Fisheries Service, \\ National Oceanic and Atmospheric Administration, 2725 \\ Montlake Blvd E, Seattle, WA 98112, USA
}


monitoring and early detection efforts. Our result underlines the small window of opportunity for Arctic conservation strategies targeting an AIS free Arctic. We recommend management that focuses on longdistance connectivity, keeping urban sources free of AIS. We discuss applicability of the approach for other data-limited situations supporting data-informed AIS management responses.

Keywords Aquatic invasive species - Arctic . Aviation · Elodea $\cdot$ Pathway $\cdot$ Wilderness

\section{Introduction}

Protecting wilderness ecosystems from biological invasion requires data-driven decisions, often made possible through a participating public (Auffret and Cousins 2013; Bullock et al. 2018; Encarnação et al. 2021; Runghen et al. 2021). Yet, too often the global and local processes that drive fast-paced environmental change in Earth's remotest regions remain largely unexplored (Huntington et al. 2020). This data scarcity is most symptomatic where large tracts of natural environment remain (Gaulke et al. 2019). Remoteness and the associated high cost of monitoring and data collection can lead to additional management challenges (Schwoerer et al. 2021). These management challenges are exacerbated when the invader is difficult to detect and thus more likely to be established before detection, as is often the case with aquatic invasive species (AIS) (Sytsma and Pennington 2015). Especially in as yet undisturbed wilderness areas, a better understanding of human travel patterns as pathways for invasive species is essential for effective early detection and eradication (McGeoch et al. 2016; Runghen et al. 2021).

Much of the research into the human-mediated overland spread of AIS has focused on relatively local activities, such as recreational boating (Johnson et al. 2001; Leung et al. 2006; Muirhead et al. 2009). Longdistance dispersal through aircraft also occurs and can accelerate the rate of spread across vast and remote landscapes but has received less attention than surface transport (Marco et al. 2011). Previous efforts at forecasting human pathways have used gravity models (Leung et al. 2006; Carrasco et al. 2010), economic recreation demand models (Chintakayala et al. 2010), and probabilistic Bayesian models (Stanaway et al. 2011; Douma et al. 2016). However, many of these models can be data intensive and misaligned with resource managers need for quick data-driven decision support (Panetta and Gooden 2017).

This study was motivated by the discovery of Elodea spp. (Elodea), in Alaska, United States (Carey et al. 2016). Elodea is Alaska's first submerged freshwater aquatic invasive plant with the earliest documented Alaska records from Eyak Lake, Cordova, southcentral Alaska in 1982 (Professional Fisheries Consultants 1985) and from Chena Slough, Fairbanks, interior Alaska in 2010 (Carey et al. 2016). In 2015 Elodea was found in Anchorage's Lake Hood, the world's busiest floatplane base ${ }^{1}$ with over 1000 stationed aircraft (Hollander 2015). Since Alaska is mostly roadless, small single-engine propeller driven fixed-wing aircraft play a large role in meeting statewide transportation needs. During summer months, hundreds of aircraft are converted to floatplanes, which include flying boats and pontoon planes with float landing gear. ${ }^{2}$ Since the discovery of Elodea in Lake Hood, Elodea has spread from urban sources to remote waterbodies (Carey et al. 2016; Schwoerer and Morton 2018). Infestations start below the water surface and are difficult to detect. Once established, Elodea creates safety hazards for floatplane pilots and can cause significant ecological and economic damage (Schultz and Dibble 2012; Schwoerer et al. 2020).

Given the lack of pathway data, the submersed nature of the plant, and the urgency of management response, the objective of the study was to quickly collect pathway data and to inform early detection and rapid response. Our approach relied on a survey of floatplane pilots to collect flight patterns and quantify risk of spread using a Bayesian hierarchical model suitable for data-limited situations (Gelman et al. 2013; Leung and Steele 2013). Here we outline the developed data collection and modeling approach and present model evaluation and results that inform current and future Elodea management. Specifically, we used hypothetical "what-if" scenarios to illustrate the usefulness of the model to inform future management action. We conclude with a discussion of the

\footnotetext{
${ }^{1}$ Floatplane bases are floatplane airports in waterbodies near human population centers.

${ }^{2}$ Amphibius planes are a third category which have landing gear for both water and land.
} 
relevance of the results and applicability of the approach for other data-limited situations.

\section{Materials and methods}

Sample

Our approach is related to previous AIS survey research from the Great Lakes, USA (Leung et al. 2006; Muirhead et al. 2009) that used voluntary geographic information from research participants (Haklay 2013). In summer months, a large portion of pilots fly commercially in Alaska for air taxis and charter operators but reside outside of Alaska for the remainder of the year. Thus, there is no comprehensive sampling frame that would include the contact information for all pilots flying in Alaska in any given year. The sampling then considered three groups to achieve adequate coverage: (1) private pilots who fly floatplanes for personal reasons, (2) commercial pilots, and (3) government agencies such as federal land management and state law enforcement. For Group 1, we relied on the Federal Aviation Administration's (FAA) Airmen Certification Releasable Database including physical addresses and license information. We drew a stratified random sample of 1015 from 2625 floatplane-certified pilots residing in Alaska (FAA 2015). ${ }^{3}$ Division of the rural and urban strata followed U.S. Census designations and we oversampled the rural strata by contacting all listed pilots (Online Resource 1 Table 4) (U.S. Census Bureau 2010).

For Group 2, we used the Directory of Alaska Flight Operations, a list of air taxi, charter, and lodge operators (FlyAlaska 2015), supplemented by the Alaska business license database within the transportation, recreation, and hunting/fishing lines of business (DCCED 2015). If the company name indicated the use of planes, we included it, then narrowed the list of 388 contacts to 80 floatplane operators through telephone and web confirmation (Table 1). Finally, for Group 3, an AIS interagency working group created a list of 64 floatplane pilots employed by state and federal agencies (Table 1). We

\footnotetext{
3 According to the FAA, opt-out rates related to pilots not wanting their personal information and addresses published in this database are minimal. We also checked for address accuracy.
}

excluded floatplane pilots and charter businesses located in Southeast Alaska and the Aleutian Islands where regional operations in marine waters reduce the risk of Elodea transmission. Flights originating in saltwater provide a natural risk buffer to the spread of Elodea, which is intolerant to saltwater (Cook and Urmi-König 1985).

\section{Survey design}

The main goal of the survey was to quickly identify as many unique floatplane destinations as possible and associate flight origin and annual flight frequencies for predictive modeling. We designed an electronic mapping tool programmed in JavaScript and using Mapbox Outdoors general-purpose maps, enabling precise location of flying destinations (Online Resource 1 Fig. 5) (Haklay 2013). We asked pilots to identify their home base and mark their 2015 firstleg freshwater destinations. Once respondents placed the electronic marker, a pop-up menu asked respondents to estimate the number of flights in 2015 to the marked destination using the following intervals $<10,10-25,25-50,50-75,75-100$, and $>100$.

Ten key informant interviews refined the survey and flight frequency intervals and helped justify our focus on first-leg flights. Most Alaska floatplane pilots in Group 1 have a few known destinations that they frequently fly to round trip, limiting the number of multi-destination flights (Schwoerer et al. 2020). For this reason and to keep data collection and analysis straight forward, we did not investigate multi-destination flights. We defined the first-leg two-way flight pattern as a flight trip for further analysis.

The online questionnaire opened with an awareness section informing pilots about the safety hazards of Elodea followed by the mapping tool and sociodemographic questions. To prevent double counting, the survey distinguished among personal, commercial, and government related flights. The survey was administered between December 2015 and May 2016 using an online survey platform (Qualtrics 2021).

\section{Data collection and compilation}

The three group samples required mixed-mode data collection consisting of mail, email, and telephone contacting (Lavrakas 2008). We first contacted Group 
Table 1 Response rates and flight counts by pilot group

\begin{tabular}{lllllll}
\hline Group, N & $\begin{array}{l}\text { Primary survey } \\
\text { mode }\end{array}$ & $\begin{array}{l}\text { Effective } \\
\text { sample }\end{array}$ & $\begin{array}{l}\text { Response count } \\
\text { (rate) }\end{array}$ & $\begin{array}{l}\text { Mapping } \\
\text { count }\end{array}$ & $\begin{array}{l}\text { Total flight } \\
\text { counts }\end{array}$ & $\begin{array}{l}\text { Flight counts from AIS sources } \\
(\% \text { of total })\end{array}$ \\
\hline $\begin{array}{l}\text { Personal, } \\
2625\end{array}$ & Mailed invite & $1000^{(\mathrm{a})}$ & $444(44 \%)^{(\mathrm{b})}$ & 221 & 8133 & $2464(27 \%)$ \\
$\begin{array}{l}\text { Commercial, } \\
80\end{array}$ & Telephone & 80 & $52(66 \%)^{(\mathrm{c})}$ & 52 & 15,761 & $6240(70 \%)$ \\
$\begin{array}{l}\text { Government, } \\
64\end{array}$ & Emailed invite & 64 & $38(59 \%)$ & 38 & 3008 & $259(3 \%)$ \\
Total & & 1144 & $534(47 \%)$ & 311 & 26,902 & 8963 \\
\hline
\end{tabular}

${ }^{(a)}$ Excludes 15 initial mailings that were undeliverable.

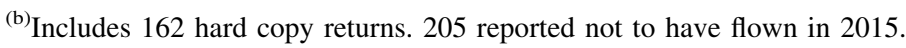

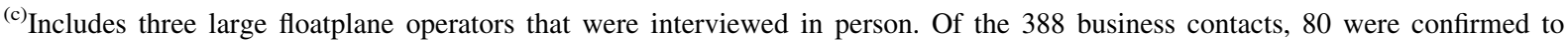
operate floatplanes, 173 were confirmed not to operate floatplanes, 118 were out of business by the time contacted, 16 were not reachable, and one contact manufactured floatplane parts and was excluded

1, using a mailed letter of invitation with individualized URL and US\$2 incentive payment. The second contact was a post card reminder, and the third contact included a reminder letter, paper copy of the questionnaire, and stamped return envelope for respondents without Internet access (Dillman 2007; Hudson 2015). ${ }^{4}$ We finally called contacts by phone using phone numbers purchased from a private marketing firm matching FAA-published addresses.

We first contacted Group 2 through an email invitation with personalized URL and then followed up by phone, screening out operators without floatplanes. We then attempted to interview respondents over the phone, digitizing their responses directly using the online survey instrument. Upon respondent request, we either sent a paper copy by mail including a stamped return envelope or provided a personalized short-URL over the phone. For very large floatplane operations, we conducted in-person interviews with the person most familiar with flight operations. We contacted Group 3 up to three times through email and finally with a phone follow up.

For data quality assurance, we edited marked destinations that were placed on land to the nearest waterbody at the HUC8 level of the USGS National Hydrographic Dataset (NHD) (USGS 2017), and established a unique ID for each NHD waterbody

\footnotetext{
$\overline{4}$ In 2011, 70\% of Alaska households had Internet connections over $200 \mathrm{kbps}$. The extent of current high-speed Internet is unknown but in the most recent data available, was slower in rural Alaska compared to urban centers (FCC 2012).
}

(Schmidt and Schwoerer 2020). Flight trips that contained a marine or runway location (used by amphibious airplanes) were eliminated. For empirical analysis, we used the midpoint of the survey's flight frequency interval. Lastly, we assigned each waterbody to one of eight regions roughly encompassing HUC6 watersheds (USGS 2017) in order to compare risk across Alaska regions (Fig. 1). The dataset is archived at the National Science Foundation's Arctic Data Center (Schwoerer 2020). The code to data, analysis and preparation of figures is available in Online Resource 2.

\section{Empirical model and Bayesian inference}

We define two related measures of AIS introduction risk as introduction probability $\theta$ and the number of expected flights from AIS sources. We refer to AIS as the subset of aquatic invasive plants with aircraft transmission potential similar to Elodea (e.g. Brazilian waterweed (Egeria densa) or Eurasian Watermilfoil (Myriophyllum spicatum) (Kent et al. 2018). Thus, we use AIS and Elodea interchangeably for the remainder of the paper. The term AIS transmission refers to the general processes involved in carrying AIS from one lake to another. We use the term lake to mean any floatplane accessible waterbody in freshwater in either standing or flowing water with a fetch distance of at least $336 \mathrm{~m}$ (Schmidt and Schwoerer 2020).

For the empirical analysis we used a Bayesian hierarchical approach generally suitable for estimating 


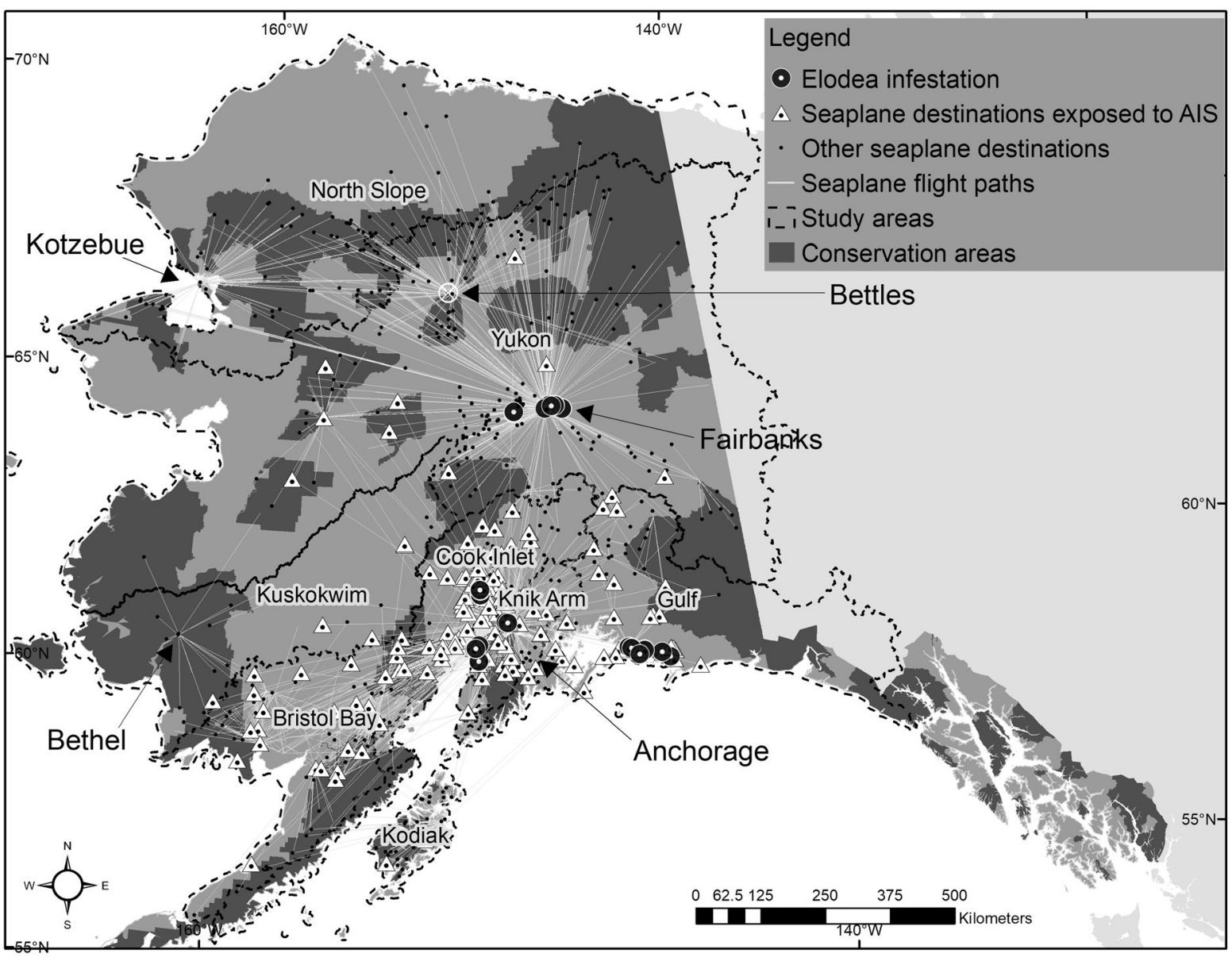

Fig. 1 Floatplane flight paths from a 2015 survey with floatplane pilots showing reported origin and destinations. Conservation areas include National Parks, National Wildlife Refuges, and designated wilderness within National Forests

uncertainty in data-limited situations with small sample sizes (Gelman et al. 2013). Here, we developed a model that estimates the parameter of interest, AIS introduction risk, for each of 682 lakes. All 682 lake introduction risk parameters are related or connected in some way to the flight patterns largely centered around urban floatplane bases (Fig. 1). Thus, the aim of the joint probability model for all 682 parameters is to capture how each parameter is inter-dependent and structured around the network of flights. With help of the hierarchical structure, which modeled flights within lakes, we are able to borrow information from the overall data to estimate uncertainty surrounding parameters with small sample sizes (Gelman et al. 2013).

First, we constructed hierarchical models to estimate the AIS introduction probability to lake $j$ as $\theta_{j}$, given flights from AIS sources, $y$, and total flights, $n$. This framework accounted for variable numbers of flights between lakes, with those having fewer flights being more uncertain probabilities of transmission. To maintain simplicity and to address a relative lack of data on existing condition of waterbody, we ignored the probability that a given flight from an Elodea source is carrying Elodea and ignored the probability that conditions in the arriving waterbody are suitable for Elodea. Thus, introduction probability $(\theta)$ served as a proxy. Second, since propagule pressure is an important risk factor aside from introduction probability $\theta$, we also estimated the expected number of flights from AIS sources equal to the mean introduction probability $\theta$ multiplied by flights, $n$.

We fit two models. The first assumed that invasion probabilities for each waterbody were independent (no 
pooling) and the second assumed that parameters across floatplane accessible waterbodies were drawn from a shared or hierarchical distribution (partial pooling for repeated binary trials). The first model, without pooling, modeled the AIS introduction probability $\left(\theta_{j}\right)$ as independent. Thus, lakes with more flights $(n)$ have more precise invasion probability estimates compared to lakes with fewer flights. In contrast, the hierarchical partial pooling model assumes that each lake is different but shares similarities with other lakes connected in some way by underlying but unknown processes (e.g. human behavior) or structure (e.g. lake characteristics such as fishing quality). ${ }^{5}$ Thus, the probability that lake $j$ is invaded, $\theta_{j}$, is assumed to be related to the estimates of the $\theta_{j}$ 's for other lakes. For each lake $j=1, \ldots J$, $J=682$ we observe $y_{j}$ flights originating from AIS source lakes out of the total number of flights $n_{j}$ to lake $j$. The hierarchical or partial pooling model has the advantage that estimates from more data rich lakes can help inform lakes with few flights while allowing more uncertainty surrounding estimates with sparse data (Carpenter et al. 2017).

The probability distribution for each lake's number of flights from AIS source lakes, $y_{j}$ is modeled through the Binomial likelihood (logit link) as follows using $\log$-odds $\alpha_{j}$

$p\left(y_{j} \mid \alpha_{j}\right)=\prod_{j=1}^{J} \operatorname{Binomial}\left(y_{j} \mid n_{j}, \operatorname{logit}{ }^{-1}\left(\alpha_{j}\right)\right)$

where $\alpha_{j}=\operatorname{logit}\left(\theta_{j}\right)=\log \frac{\theta_{j}}{1-\theta_{j}}$ is the logit transform and $\operatorname{logit}^{-1}\left(\alpha_{j}\right)=\frac{1}{1+\exp \left(-\alpha_{j}\right)}=\theta_{j}$ is the inverse logit function, back-transforming log-odds to probability. For the hierarchical model, the population of invasion rates is assumed to be normally distributed in logitspace, such that $a_{j} \sim \operatorname{Normal}\left(0, \sigma_{a}\right)$.

For the no pooling model, we applied a weakly informative prior on the log-odds as follows $\alpha_{j-}$ $\sim$ Normal $(-1,1)$. For the partially pooled model, we applied a non-informative (flat) prior on the logodds as follows $\alpha_{j} \sim \operatorname{Normal}(0,1.4)$ and $\alpha_{0} \sim$ Normal $(0,1.4)$ (King et al. 2009), where $\alpha_{0}$ are the logodds associated with a global intercept (Carpenter et al. 2017). ${ }^{6}$ Using $\sigma=1.4$ results in a prior that when

\footnotetext{
5 Note, a complete pooling model would not make sense here, because by definition the chance of success parameters are all the same (Carpenter et al. 2017).
}

transformed with the inverse-logit function is flatter than when $\sigma=1.0$. As a prior sensitivity, we compared these results to those using a weakly informative prior, $\boldsymbol{\alpha} \sim \operatorname{Normal}(-1,1)$, for the partial pooling model. We fit both models using the R package rstanarm with stan_glm and stan_glmer functions respectively (Carpenter et al. 2017; Goodrich et al. 2020) (Online Resource 2). For sampling from the joint posterior distribution of parameters, we used 10,000 samples per chain, 3 chains, and set the target acceptance rate to 0.99 (Goodrich et al. 2020).

Hypothetical scenarios

Due to the vicinity of Elodea infestations in the Fairbanks area there is heightened concern that Fairbanks floatplane bases could become sources through other human pathways such as aquarium dumping. For this reason, we analyzed a hypothetical scenario with the Fairbanks Floatpond as an Elodea source by altering the Elodea invasion variable in our data to indicate a hypothetical invasion before running the model and presenting the results as outlined.

Additionally, we created a scenario to show the benefits of eradicating Elodea from floatplane bases in regional hubs, including Lake Hood and Sand Lake (Knik Arm region), Big Lake (Cook Inlet), and Eyak Lake (Gulf of Alaska) (Fig. 1). To accomplish this simulation, we first altered the dataset to change the invasion status of the four lakes from invaded to uninvaded. We then compared scenario results visually to the model results without this alteration (Online Resource 2).

\section{Model evaluation}

We first compared models focusing on the relative predictive accuracy using cross-validation available in R's loo package (Vehtari et al. 2017). For each model, we approximated the expected log predictive density (ELPD) through the leave-one-out function (loo), giving the ELPD difference between models (Vehtari et al. 2017). Further evaluation used the bayesplot package (Gabry et al. 2019) to visualize predictive checks and model results. First, we visually

\footnotetext{
${ }^{6}$ stan_glmer uses this global intercept to get the posterior distribution for each $\alpha_{j}$ (Carpenter et al. 2017; Goodrich et al. 2020).
} 
investigated whether the replicated data from each model was more extreme than the observed data. We then looked at histograms of test statistics, such as mean and standard deviation of the replicated data, comparing them against the value of the statistic computed from observed data. In addition, we generated fifteen replicated datasets from fitted parameters of the best fitting model and visually compared them to the observed dataset used to fit the model (Gelman et al. 2013; Carpenter et al. 2017).

Lastly, we evaluated predictive accuracy by investigating the posterior predictive distributions for known Elodea-invaded lakes where floatplanes are believed to be the most likely pathway. We then evaluated posterior sampling quality for the best performing model by visually checking conversion of iterative simulations to a common distribution (Gabry et al. 2019), comparing the effective sample size with the actual sample size used to draw from the posterior (Gelman et al. 2013). We also checked chain convergence using the Monte Carlo standard error (MCSE) and the $\hat{R}$ statistic (Gelman and Rubin 1992). For parameters with the smallest effective sample size, we visually checked convergence, highlighting divergences in traceplots (Gabry et al. 2019).

\section{Results}

Survey response and data

The mixed mode survey achieved an overall $47 \%$ response rate with the highest response rate observed among commercial operators (Table 1). About a third (8963) of total reported flight trips $(26,902)$ originated in an AIS source lake, with the largest percentage being commercial $(70 \%)$ (Table 1). Survey respondents identified over 682 unique floatplane accessed freshwater locations of which 72 were floatplane bases (Fig. 1, Table 2). The survey identified a wide distribution of floatplane destinations across Alaska, (Fig. 1, Table 2). Based on survey results we estimate that in Alaska 164,638 (16\%) of $>1$ million waterbodies across a land area equal to $443,000 \mathrm{~km}^{2}$ are accessible by floatplane (Schmidt and Schwoerer 2020). Knik Arm, Cook Inlet, and the Gulf of Alaska regions are among the most floatplane-accessible regions near Anchorage, Alaska's population center (Tables 2 and 3, Fig. 1).

We used operations data from Lake Hood as the only Alaska floatplane base monitored by the FAA, to estimate that our survey covered more than $80 \%$ of the actual floatplane operations in 2015. Lake Hood offers space for approximately 1000 aircraft, of which $40 \%$ are converted to floatplanes in summer (Schwoerer et al. 2020, Alaska Department of Transportation 2020 personal communication). Assuming that the average floatplane season lasts from mid-April to mid-October, the FAA counted 27,722 takeoffs at Lake Hood during this time period in 2015 (FAA 2016). If we apply the $40 \%$ floatplane ratio to the Lake Hood operations count, this calculation yields 11,000 floatplane take-offs to marine and freshwater locations of which the survey captured 8546 flights to freshwater destinations, thus amounting to more than $80 \%$ of true operations.

Two floatplane bases, Anchorage's Lake Hood and Fairbanks' Floatpond, ${ }^{7}$ are the most frequented and also reach the most regions and destinations (Table 3). Pilots operating out of these two floatplane bases access over half of the 682 reported floatplane accessible waterbodies, emphasizing their critical role in reducing risk of AIS spread. Three quarters of all reported Lake Hood flights are destined for Cook Inlet, followed by Bristol Bay (12\%), Knik Arm (10\%), Kuskokwim $(<1 \%)$, and Yukon $(<1 \%)$. The largest proportion of flights originating at the Fairbanks Floatpond are destined for the Yukon region (77\%), North Slope (21\%), Kuskokwim (1\%), and Knik Arm, primarily Lake Hood (1\%). The most frequented floatplane bases in other regions have a higher proportion of intra-region flights, therefore playing a larger role as regional hubs rather than inter-region connectors (Table 3 ).

Model selection and diagnostics

The partial pooling model had the highest expected log predictive density difference (ELPD) for $\widehat{\theta}(-1382.5$, SE 40.9). We also tested the partial pooling model with a weakly informative prior (Normal $(1-, 1)$ ), which performed slightly worse (- 7.7, SE 2.6) than our preferred model with a flat prior. The graphical

\footnotetext{
7 This floatplane base is officially referred to by the FAA as the Fairbanks International Airport Floatpond.
} 
Table 2 Region characteristics, floatplane bases, and high-risk floatplane destinations by region

\begin{tabular}{|c|c|c|c|c|c|c|c|}
\hline \multirow[t]{2}{*}{ Region } & \multirow[t]{2}{*}{ Land area size $\mathrm{km}^{2}$} & \multicolumn{2}{|c|}{ Waterbodies in NHD } & \multicolumn{4}{|c|}{ Waterbodies in survey } \\
\hline & & Total count & $\%$ accessible $^{(a)}$ & Floatplane Bases & Total count & High risk ${ }^{(b)}$ & $\%$ High risk \\
\hline Bristol Bay & 53,297 & 126,394 & $10 \%$ & 13 & 72 & 5 & $7 \%$ \\
\hline Cook Inlet & 53,375 & 38,165 & $20 \%$ & 23 & 183 & 81 & $44 \%$ \\
\hline Gulf of Alaska & 54,366 & 51,597 & $20 \%$ & 7 & 60 & 21 & $35 \%$ \\
\hline Knik Arm & 12,629 & 2,019 & $48 \%$ & 13 & 26 & 12 & $46 \%$ \\
\hline Kodiak & 44,028 & 15,271 & $10 \%$ & 1 & 15 & 2 & $13 \%$ \\
\hline Kuskokwim & 75,744 & 182,194 & $17 \%$ & 2 & 28 & 2 & $7 \%$ \\
\hline North Slope & 34,444 & 238,274 & $18 \%$ & 1 & 92 & 0 & $0 \%$ \\
\hline Yukon & 115,544 & 360,549 & $16 \%$ & 12 & 206 & 2 & $1 \%$ \\
\hline Total & 443,427 & $1,014,463$ & $16 \%$ & 72 & 682 & 125 & $18 \%$ \\
\hline
\end{tabular}

${ }^{(a)}$ Percentage of all NHD waterbodies characterized as floatplane accessible. Schmidt and Schwoerer (2020) defined floatplane accessibility as waterbody fetch exceeding $336 \mathrm{~m}$.

${ }^{(b)}$ High risk waterbodies are defined as the median AIS introduction probability exceeding 0.5

Table 3 Flight frequencies by destination region for the most frequented floatplane bases per region, 2015

\begin{tabular}{|c|c|c|c|c|c|c|c|c|c|c|}
\hline $\begin{array}{l}\text { Floatplane } \\
\text { base }\end{array}$ & Region & $\begin{array}{l}\text { Bristol } \\
\text { Bay }\end{array}$ & $\begin{array}{l}\text { Cook } \\
\text { Inlet }\end{array}$ & $\begin{array}{l}\text { Gulf of } \\
\text { AK }\end{array}$ & $\begin{array}{l}\text { Knik } \\
\text { Arm }\end{array}$ & Kodiak & Kuskokwim & $\begin{array}{l}\text { North } \\
\text { Slope }\end{array}$ & Yukon & Total \\
\hline Lake Hood ${ }^{(a)}$ & Knik Arm & 995 & 6,483 & 158 & 846 & & 58 & & 60 & 8600 \\
\hline $\begin{array}{c}\text { Fairbanks } \\
\text { Float }\end{array}$ & Yukon & 10 & 10 & 10 & 23 & & 15 & 455 & 1693 & 2216 \\
\hline $\begin{array}{l}\text { Salamatof } \\
\text { Lake }\end{array}$ & Cook Inlet & 23 & 893 & & & & 5 & & & 921 \\
\hline Lake Clark & Bristol Bay & 743 & 1 & & 5 & 5 & 58 & & & 812 \\
\hline Kotzebue Air & North Slope & & & & & & & 368 & 25 & 393 \\
\hline Bethel & Kuskokwim & 18 & & & & & 194 & & & 212 \\
\hline$\underset{(a, b)}{\text { Eyak Lake }}$ & Gulf of AK & & & 125 & & 1 & & & & 126 \\
\hline Lilly Lake & Kodiak & & 5 & & 5 & 56 & & & & 66 \\
\hline
\end{tabular}

(a) Known AIS source lake.

(b) The second most frequented floatplane base in the Gulf of Alaska region. It was included due to its Elodea invasion and consequently high transmission risk. Note, a comprehensive table with flights from all floatplane bases can be found in Online Resource 4

posterior predictive checks also showed the partial pooling model outperformed the no pooling model (Online Resource 1 Fig. 6). The no pooling model overestimated AIS introduction risk for waterbodies receiving no flights from AIS sources and underestimated this risk for waterbodies receiving all flights from AIS sources. The partial pooling model performed better in this regard, fitting $\widehat{\theta}$ closer to observed data and describing uncertainty in the predicted estimates.
The partial pooling model also performed well for predicting AIS introduction probabilities that are near the overall mean of 0.2 for the observed data, and close to 0 and 1.0 (Online Resource 1 Fig. 7). The model adequately predicted the range of AIS introduction probabilities, slightly underpredicting the standard deviation (median $\mathrm{sd}_{\text {mod }}=0.365$ versus $\mathrm{sd}_{\mathrm{obs}}=0.37$ ) (Online Resource 1 Fig. 7). The histograms for fifteen replicated datasets showed distributions nearly identical to the observed (Online Resource 1 Fig. 8). 

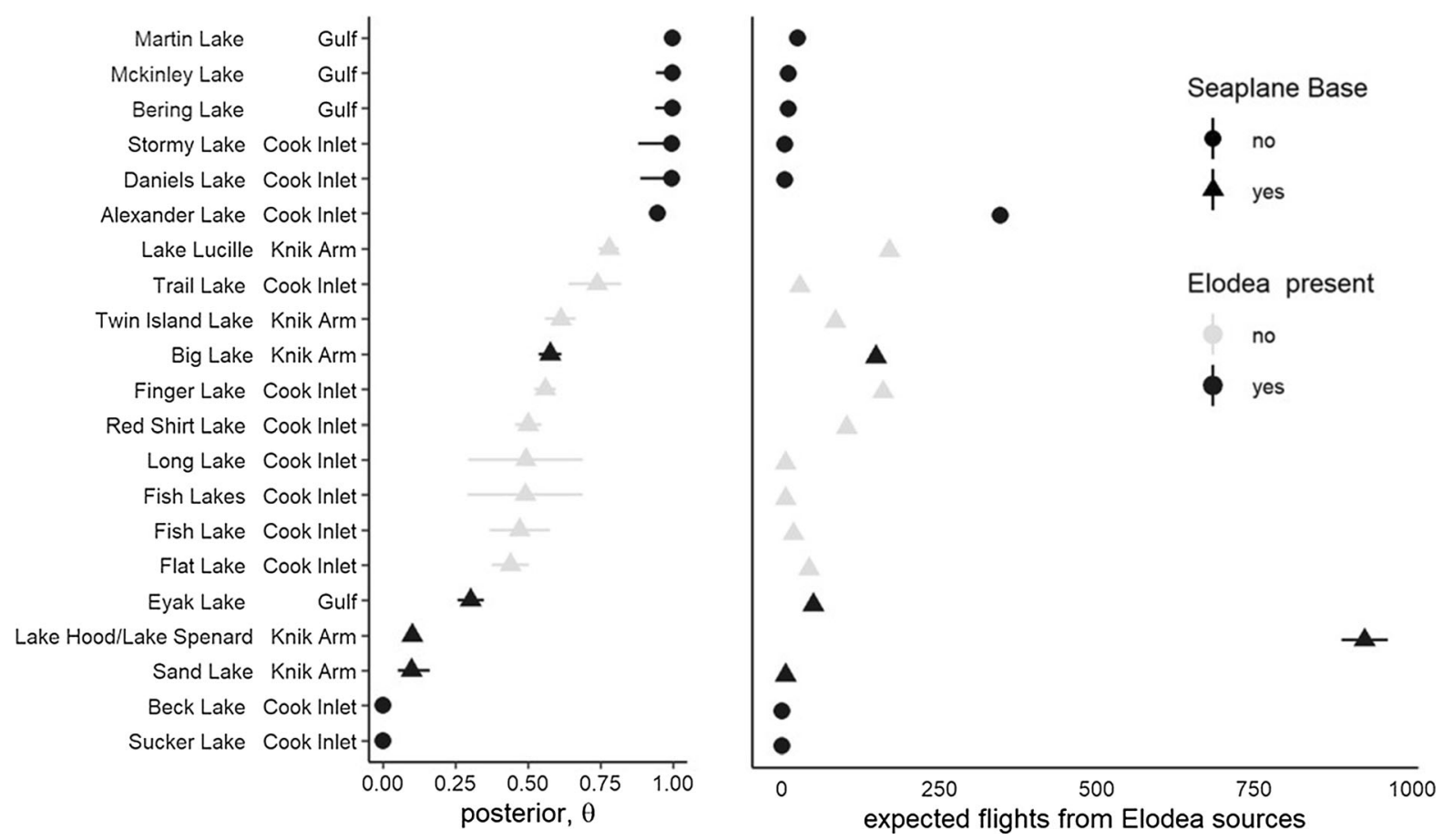

Fig. 2 Left panel: estimated posterior probability distributions for floatplane-related AIS introduction probability, $\theta_{j}$, showing the median probability and $80 \%$ credible intervals by lake name and region and right panel: expected flights from Elodea sources

Diagnostics to check sampling of the posterior for the partial pooling model revealed that 10,000 iterations, with $5000 \mathrm{kept}$ after warm-up, provided a sufficient sample size to draw from the posterior. The Monte Carlo standard errors (MCSE) were equal to zero and $\hat{R}<1.05$ for all 682 parameters indicating that the chains that sampled the posterior distribution converged. Due to autocorrelation in the draws, we compared the effective posterior sample size with the actual sample size used to draw from the posterior, finding 57 of the 682 parameters had an effective sample size lower than $10 \%$ of the total sample size $n_{\text {eff }} / N<0.1$, a common threshold for sampling quality. Thirty of these 57 parameters were associated with floatplane bases (Online Resource 1 Fig. 9). However, trace plots for the three parameters with the lowest effective sample size showed visual convergence suggesting sampling quality to be sufficient (Online Resource 1 Fig. 10).

\section{Model results}

The model predicted non-zero median AIS introduction probabilities $(\widehat{\theta})$ for 47 of the 72 floatplane bases.
The amount of uncertainty varied and was generally larger for more remote floatplane bases that receive fewer flights (Online Resource 1 Fig. 11 and 12, Online Resource 4). While none of the floatplane bases had $\widehat{\theta}$ close to 1.0 , seven bases had $\widehat{\theta}$ higher than 0.5 (Fig. 2). Based on our second measure of risk, the expected number of flights from Elodea sources, Lake Hood and Alexander Lake stand out as waterbodies that are particularly at risk of AIS introduction with over 300 expected flights from Elodea sources annually (Fig. 2).

Twelve of the 682 waterbodies that pilots identified have known Elodea invasions. Among the waterbodies where floatplane transmission was the most likely pathway, the model predicts high AIS introduction probabilities $\widehat{\theta}$ (Fig. 2). These lakes include Martin Lake, Bering Lake, and McKinley Lake which exclusively receive flights from the Eyak Lake floatplane base in Cordova, Alaska, an Elodea source lake. Thus, the expected number of flights from Elodea sources is relatively low for these remote lakes that only received a few dozen flights per year (Fig. 2). Similarly, high $\widehat{\theta}$ and low expected flights from Elodea sources were found for long-distance introductions that occurred 
Cook Inlet

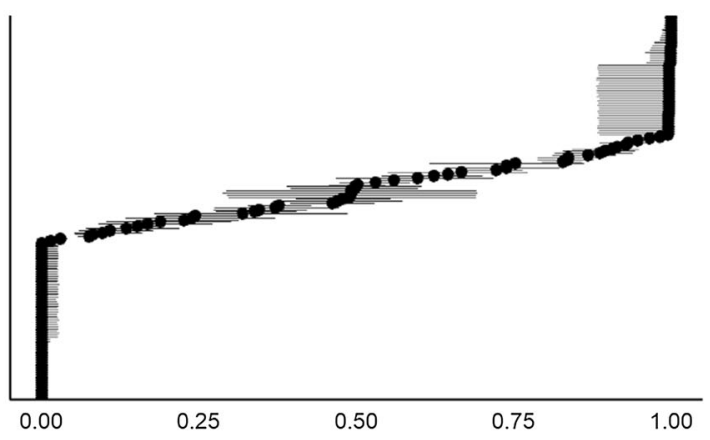

Knik Arm

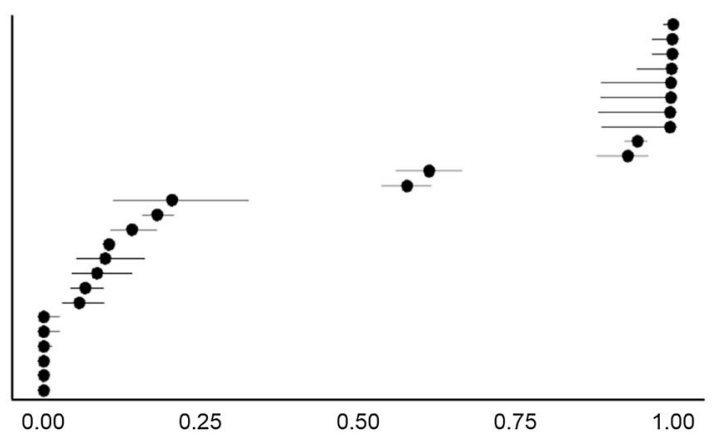

Kuskokwim
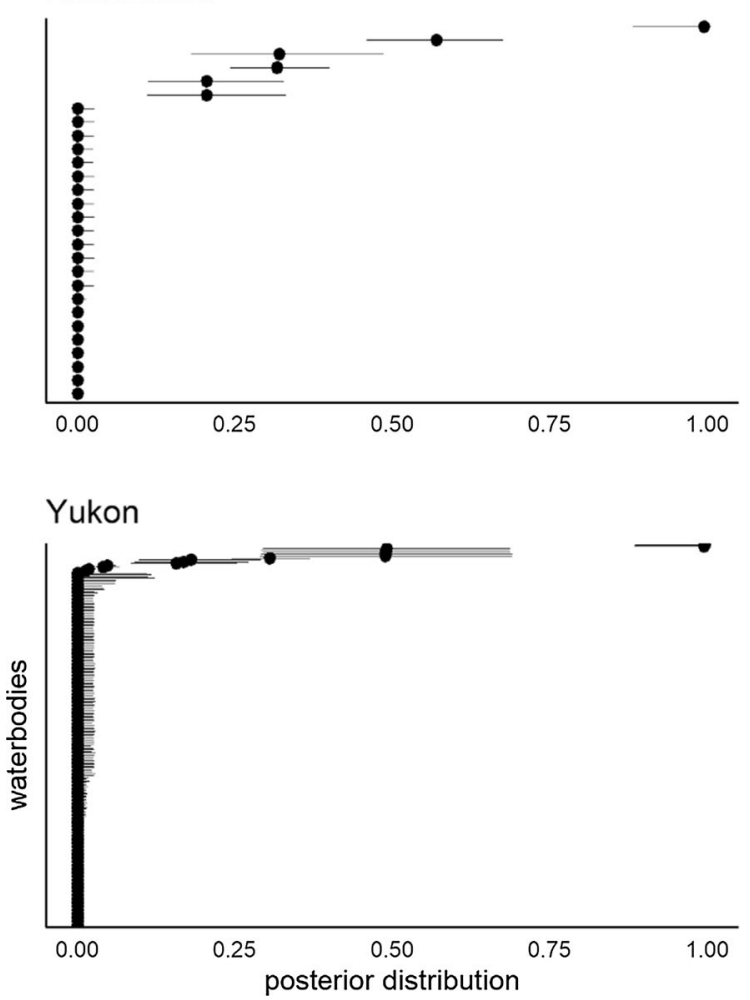

Gulf

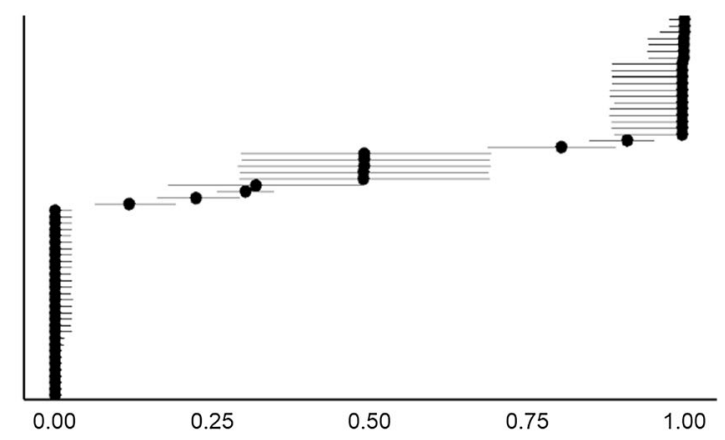

Kodiak

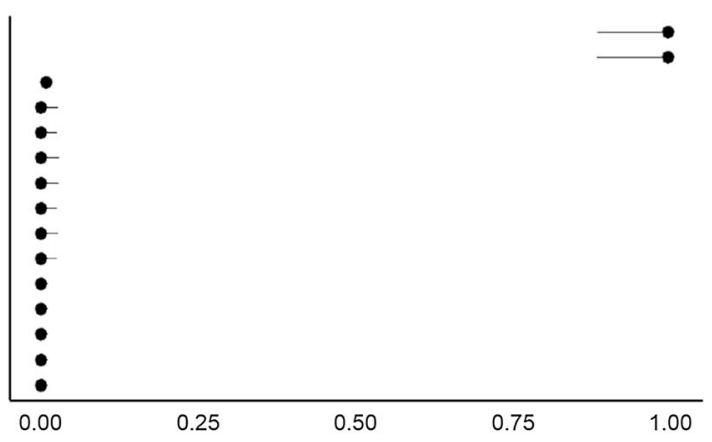

Bristol Bay

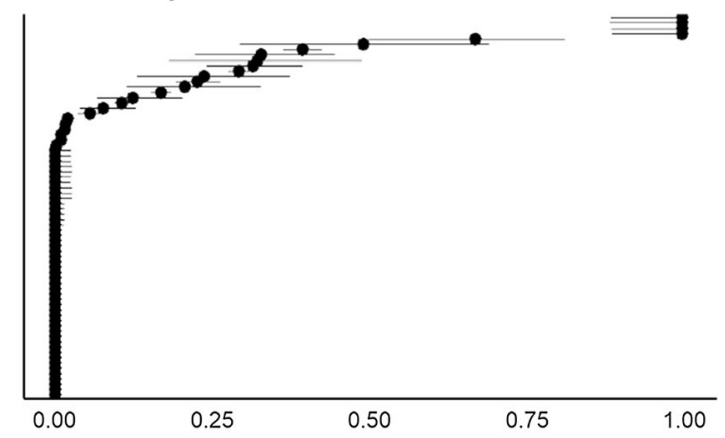

North Slope

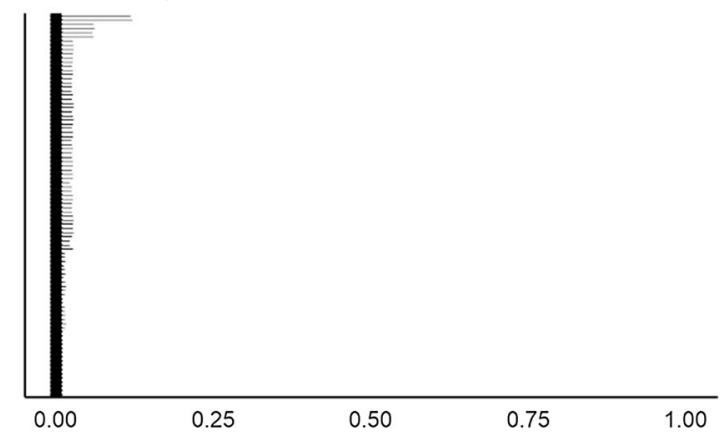


4Fig. 3 Posterior probability distributions for AIS introduction probability for all 682 floatplane waterbodies by Alaska region showing the median probability (bullets) and $80 \%$ credible interval (lines)

with two lakes in the Cook Inlet region, Alexander Lake and Big Lake, and two lakes in the Cook Inlet Region, Daniels Lake and Stormy Lake.

Results by region

Based on the expected number of flights from Elodea sources, floatplane accessible waterbodies in Cook Inlet, Knik Arm, and Bristol Bay are at highest risk of Elodea transmission with hundreds of expected flights from Elodea sources (Online Resource 1 Fig. 13). Our model predictions show that all regions except for the North Slope contain at least one waterbody with the highest median AIS introduction probability $\widehat{\theta} \geq$ 0.999. All waterbodies on the North Slope have $\widehat{\theta} \leq$ 0.001 (Fig. 3). The model predicts $\widehat{\theta}$ above 0.5 for approximately half of floatplane destinations in Cook Inlet, Gulf of Alaska, and Knik Arm (Fig. 3). There are currently no known Elodea infestations in the Kodiak, Kuskokwim, and Bristol Bay regions, but the

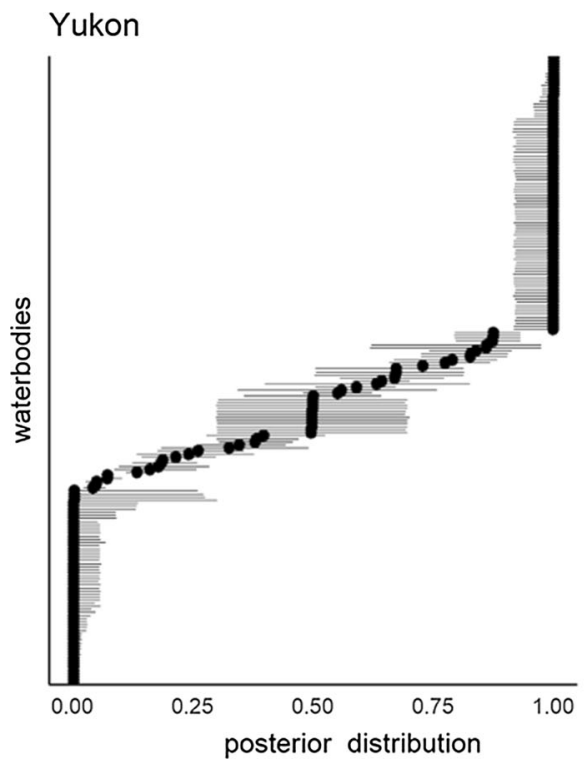

Fig. 4 Posterior probability distributions for AIS introduction probability in the hypothetical scenario that the Fairbanks International Airport Floatpond becomes a source lake in model predicts several destinations with very high $\widehat{\theta}$ located in conservation areas (Figs. 1 and 3). In the Yukon region, currently none of the known Elodea infestations are in waterbodies used by floatplanes. However, due to the presence of natural and other human pathways, these infestations could become AIS sources for waterbodies used by floatplanes. In the Yukon region, the model predicts few floatplane destinations to have $\widehat{\theta}$ above 0.5 (Fig. 3).

Although thermal characteristics in the Arctic could reduce colonization probability (Luizza et al. 2016), the spread of AIS into regions (e.g., North Slope) currently free of such species could by facilitated through the invasion of any interconnected floatplane base. Floatplane bases such as the Fairbanks Floatpond, Bettles Floatpond, and Kotzebue Airport Lake are main gateways to Arctic destinations in the North Slope region (Fig. 1). The Fairbanks Floatpond has $\widehat{\theta}$ $=0.02$ with an $80 \%$ credible interval of 0.015 and 0.022, whereas the Bettles Floatpond and Kotzebue Airport Lake both have very low introduction probabilities $(\widehat{\theta}=0.00$; CI: $0.00,0.001)$. These results imply that those three floatplane bases, given the known Elodea infestations, are less likely to become invaded through the floatplane pathway. Similar predictions hold for two additional floatplane bases

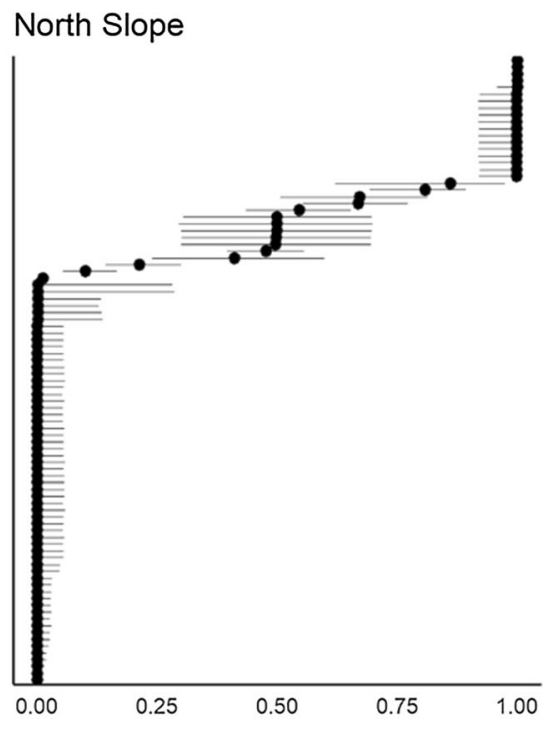

addition to currently known source lakes, the median probability (bullets) and $80 \%$ credible interval (lines) are shown for the Yukon and North Slope regions 
in Fairbanks: Metro Field $(\widehat{\theta}=0.00$; CI: 0.00, 0.02) and Chena Marina Airport $(\widehat{\theta}=0.04 ; 0.04,0.06)$.

\section{Scenario results}

Assuming an invaded Fairbanks Floatpond, this scenario shows a dramatic change from an AIS free Arctic to one facing a steep increase in the number of waterbodies at risk of invasion (Figs. 3 and 4). The number of high-risk waterbodies with a median AIS introduction probability $\widehat{\theta} \geq 0.5$ would increase from 0 to 23 , representing a quarter of floatplane destinations in the North Slope region. Similarly, waterbodies at high risk in the Yukon region would increase from 2 to 111 , encompassing more than half the identified floatplane destinations in that region (Fig. 4). This result once again underlines the importance of maintaining urban floatplane bases as AIS free and illustrates the long-range connectivity across Alaska's wilderness areas enabled by floatplanes. Preventing AIS from invading these gateways is key to keeping pristine ecosystems intact.

This result is emphasized by the second scenario that investigated the benefits of eradicating Elodea in four floatplane bases, Lake Hood, Sand Lake (both Knik Arm region), Eyak Lake (Gulf), and Big Lake (Cook Inlet). Eradication of Elodea in these floatplane bases resulted in dramatically reduced risk of AIS introduction across all 682 lakes (Online Resource 1 Fig. 14). Four of the eight regions, North Slope, Kuskokwim, Bristol Bay, and Kodiak did not indicate any AIS transmission while the other four regions showed only a few lakes with positive AIS transmission risk, largely driven by the existence of Elodea invasions in remote lakes that are capable of reintroducing Elodea into urban floatplane bases.

\section{Discussion}

Resource managers operating at global invasion fronts such as found in Arctic wilderness areas often face decisions requiring rapid response to avoid ecosystem damages but lack adequate information to support their decisions (Liu et al. 2012). Invasion management is particularly challenging for aquatic invasive species transmitted via aircraft because detection and ultimately treatment in remote waterbodies is difficult (Schwoerer et al. 2021). In this study, we showed that using a survey with human operators of mechanical invasive species vectors-in this case floatplane pilots and their flight patterns - can be used for predictive modeling to inform early detection, an approach suitable for other data-limited situations.

Our study offers a tool that achieves several objectives of adaptive management (Prato 2005). First, the survey provides for stakeholder outreach and engagement. For example, 146 respondents (13\%) were willing to volunteer for further monitoring and outreach activities related to AIS. The survey raises awareness of risk mitigating behavior, such as reminding floatplane pilots to raise and lower the rudder to disentangle aquatic vegetation before takeoff (Evans et al. 2005; Jordan et al. 2011; Crall et al. 2012). Engagement gives the public the opportunity to participate in research and decision making, encouraging others to change behavior through broader public engagement (McKinley et al. 2017).

Second, the electronic mapping tool collected data across a large spatial scale, relatively quickly, and required only modest data cleaning. The tool enabled precise location of destinations, avoiding spatial ambiguity, a prerequisite for high quality data from voluntary geographic information (Haklay 2013). Since our model does not rely on a complete understanding of the spread mechanism or range of geographic and pilot-specific information, it is modest in its data requirements, yet relevant for managers, interested in identifying vulnerable destinations based on quantitative measures of risk (Prato 2005; Tamayo and Olden 2014).

Third, the approach is suitable for analyzing data collected with multiple modes, a result of survey challenges related to the absence of a comprehensive database of pilots operating in Alaska (Gelman et al. 2013). Bayesian inference also focuses on the most important features of the dispersal pathways (Leung et al. 2006), as it improves the raw floatplane flight counts by combining them with other information, admitting more uncertainty for destinations with fewer observations (Gelman et al. 2013). The true underlying AIS introduction probabilities for different 
floatplane destinations are believed to be similar involving the same transmission process.

\section{Relevance of results}

The results showed that the two measures of risk that the study applied are both important for considering risk of introduction across a wide range of floatplane accessible waterbodies differing in the numbers of flights from AIS sources. The median AIS introduction probability $(\widehat{\theta})$ provides a more conservative measure of risk for floatplane destinations with small numbers of flights within regions where AIS already occur (e.g. Gulf of Alaska region) (Fig. 2). On the other hand, the expected number of flights serves as a second measure of risk for lakes with a large number of flights but relatively low introduction probability $(\widehat{\theta})$ therefore accounting for higher propagule pressure (e.g. Lake Hood and Alexander Lake) (Fig. 2).

Overall, model predictions are consistent with anecdotal evidence about the responsible pathways across floatplane accessible waterbodies where Elodea was found (Schwoerer and Morton 2018). The model predicted high AIS introduction probabilities $(\widehat{\theta})$ for known floatplane introductions (e.g. Alexander Lake, Big Lake, Daniels Lake, Stormy Lake) from urban source lakes (Fig. 2) (Morton et al. 2014; Hollander 2014; Coleman 2020 personal communication). The model predicted low AIS introduction probabilities $(\widehat{\theta})$ for urban source lakes (e.g. Sand Lake, Lake Hood) where other human related pathways are most likely possible (Fig. 2) (Carey et al. 2016) or for remote lakes near remote infestations (e.g. Sucker Lake in the vicinity of Alexander Lake) where natural pathways may have contributed to natural spread (Fig. 2) (Sytsma and Pennington 2015).

Model predictions show all regions contain at least one waterbody with a median predicted AIS introduction rate $\widehat{\theta} \geq 0.999$, except for the North Slope where all waterbodies have $\widehat{\theta} \leq 0.001$ (Fig. 3). The reason for this result is that survey respondents did not report any flights to North Slope waterbodies from known AIS sources. While this expected result validates the model, it also suggests that Elodea may have spread more widely across Alaska than currently known (Fig. 3).
Because the model does not account for underlying transmission mechanisms related to plant entanglement, its measure of risk approximates the true probability of introduction which is conditional on the plant being picked up and carried to suitable habitat. As a result, the modeled introduction probabilities likely overestimate the true risk of introducing Elodea. Further research extending our analysis would investigate entanglement probabilities and integrate the findings into habitat suitability models (Luizza et al. 2016).

Also, we reemphasize that our two measures of AIS introduction risk are solely related to floatplane transmission, ignoring other human and natural pathways (Carey et al. 2016). This caveat applies to other species with dispersal facilitation by human operators of mechanical vectors that are accidental, e.g. recreational boating or vehicle use including off-road vehicles (von der Lippe and Kowarik 2007; Daniels et al. 2019).

Policy recommendations and applicability

The largest AIS transmission risk originates from known Elodea source lakes in the Cook Inlet, Knik Arm, and Gulf of Alaska regions, where floatplane bases serve as inter-regional connectors, presenting higher transmission risk to other regions (Table 3). For example, Kodiak, Kuskokwim, and the Bristol Bay regions have currently no known Elodea infestations. However, model predictions point towards the existence of high-risk floatplane destinations in these regions where the median AIS introduction probability $(\widehat{\theta})$ exceeds 0.5 . Based on the number of expected flights, the Bristol Bay region is most at risk with four destinations where the expected number of flights from Elodea sources exceeds 100 flights per year (Online Resource 1 Fig. 13).

Also, unmanaged Elodea invasions in remote floatplane-accessible waterbodies present continued re-introduction risk for urban floatplane bases. The Gulf of Alaska region serves as an example where Eyak Lake is one of the most frequented floatplane bases in the region. The median AIS introduction probability for Eyak Lake $(\widehat{\theta}=0.3)$ results from the multiple remote Elodea-invaded lakes (Bering and Martin Lakes, for example), providing potential reintroduction to Eyak Lake. Since AIS transmission 
risk within the Gulf of Alaska region is predominately intra-regional (Table 3), this may explain the lack of documented spread to other regions between Elodea's first documentation in 1982 and 2010 (Professional Fisheries Consultants 1985; Carey et al. 2016). Compared to the Gulf of Alaska region, far greater risk of AIS spread is associated with the Fairbanks Floatpond, where $77 \%$ of all flights go to the Yukon region and $21 \%$ of flights go to the North Slope region (Table 3).

Maintaining floatplane bases free of AIS is critical for reducing AIS spread to valuable aquatic resources in remote regions. At the same time, immediate cleanup of Elodea-invaded remote lakes reduces risk of re-introduction to urban floatplane bases. This management action is of particular importance given effective and successful herbicide treatments of Elodea with few documented impacts on native aquatic plants (Sethi et al. 2017; Schwoerer and Morton 2018).

Spatially specific probabilistic information on AIS introduction risk also informs prevention strategies. For example, our hypothetical examples of an invaded floatplane base in Fairbanks and eradication of Elodea from infested floatplane bases showed that management strategies that focus on keeping floatplane bases free of AIS, critically prevent the spread to uninvaded waterbodies, especially to conservation areas (Fig. 1). Probabilistic information also directs managers towards destination waterbodies that may require more frequent surveys to ensure early detection.

The quantified risk is more broadly applicable to other AIS, particularly aquatic invasive plants with similar transmission processes such as Brazilian waterweed (Egeria densa) or Eurasian Watermilfoil (Myriophyllum spicatum) that are spreading north into a warming Arctic (Kent et al. 2018). Our approach is also applicable in other recreation settings including hiking (Liedtke et al. 2020), watercraft-related recreation (Leung and Mandrak 2007; Muirhead et al. 2009; Kelly et al. 2013), or vehicle-related transmission of invasive species (von der Lippe and Kowarik 2007; Daniels et al. 2019).

\section{Conclusions}

This study used an innovative electronic mapping exercise to collect data on flight patterns through public participation and estimated a Bayesian hierarchical model quantifying AIS introduction risk across approximately 700 remote waterbodies. Results show that management strategies aimed at keeping urban AIS source lakes clean, can dramatically minimize broad invasion risk across remote wilderness. The approach provides resource managers with a tool to gather information relatively quickly and less costly compared to physical surveillance and supports datadriven decision-making, overcoming data limitations often present at an invasion front. In addition, the presented survey methods are a tool for continued engagement between managers and human pathway actors. The broad public engagement achieved in this study is particularly important for implementing successful conservation strategies for wilderness areas that are threatened by biological invasions through increasing connectivity to urban human population centers. The study contributes to improved understanding of human-mediated long-range dispersal via aircraft but the approach is applicable to other human transportation-related pathways.

Acknowledgements This study would not have been possible without the dedication and trust of floatplane pilots across Alaska who shared their flight destinations with us. We would like to thank the following personnel for their contribution to the survey. Kyle Borash programmed the mapping tool, Heather Stewart and Peter Johnson assisted with the survey, Margaret Nye managed data collection, and Lauren Fritz assisted with data cleaning. We thank Dr. Milo Adkison for comments to an early draft of the manuscript and four anonymous reviewers for their constructive feedback.

Author contributions All co-authors contributed equally to the development and writing of the manuscript and are listed in alphabetical order.

Funding We received funding from the U.S. Fish and Wildlife Service [cooperative agreements F19AC00989/F19AC01010], Fairbanks Soil and Water Conservation District, Alaska Sustainable Salmon Fund [Award 44907, 2013], Alaska Sea Grant [Award R/112-03, 2014], Cook Inlet Aquaculture Association, and through in-kind contributions from the Alaska Department of Natural Resources.

Data availability The data, code, and model results are archived at the Arctic Data Center, available at https://doi.org/ 10.18739/A2N29P76G

Code availability The code file is included as Online Resource 2 and archived together with the data at the Arctic Data Center, available at https://doi.org/10.18739/A2N29P76G. 


\section{Declarations}

Conflict of interest The authors declare that they have no known competing financial interests or personal relationships that could have appeared to influence the work reported in this paper. Funding sources were not involved in the decision to publish the research.

Consent to participate Participants of the research gave electronic consent before participating in the survey as approved by the Institutional Review Board.

Consent for publication Included in the consent language for survey participants was a statement about publishing the collected data, thus participants consented to publication. All coauthors consented to the publication of the manuscript.

Ethics approval The research was approved by the University of Alaska Fairbanks and University of Alaska Anchorage Institutional Review Boards (IRB) under project 612464.

Open Access This article is licensed under a Creative Commons Attribution 4.0 International License, which permits use, sharing, adaptation, distribution and reproduction in any medium or format, as long as you give appropriate credit to the original author(s) and the source, provide a link to the Creative Commons licence, and indicate if changes were made. The images or other third party material in this article are included in the article's Creative Commons licence, unless indicated otherwise in a credit line to the material. If material is not included in the article's Creative Commons licence and your intended use is not permitted by statutory regulation or exceeds the permitted use, you will need to obtain permission directly from the copyright holder. To view a copy of this licence, visit http://creativecommons.org/licenses/by/4.0/.

\section{References}

Auffret AG, Cousins SAO (2013) Humans as long-distance dispersers of rural plant communities. PLoS ONE 8:e62763. https://doi.org/10.1371/journal.pone.0062763

Bullock JM, Bonte D, Pufal G et al (2018) Human-mediated dispersal and the rewiring of spatial networks. Trends Ecol Evol 33:958-970. https://doi.org/10.1016/j.tree.2018.09. 008

Carey M, Sethi SA, Larsen S, Rich C (2016) A primer on potential impacts, management priorities, and future directions for Elodea spp. in high latitude systems: learning from the Alaska experience. Hydrobiologia 777:1-19. https://doi.org/10.1007/s10750-016-2767-X

Carpenter B, Gabry J, Goodrich B (2017) Hierarchical partial pooling for repeated binary trials. https://mc-stan.org/ users/documentation/case-studies/pool-binary-trialsrstanarm.html\#partial-pooling. Accessed 21 Nov 2020

Carrasco LR, Mumford JD, MacLeod A et al (2010) Unveiling human-assisted dispersal mechanisms in invasive alien insects: Integration of spatial stochastic simulation and phenology models. Ecol Model 221:2068-2075. https:// doi.org/10.1016/j.ecolmodel.2010.05.012

Chintakayala PK, Hess S, Rose J, Wardman M (2010) Effects of stated choice design dimensions on estimates. In: Hess $\mathrm{S}$, Daly A (eds) Choice modelling: the state-of-the-art and state-of-practice. Emerald Group Publishing Limited, Bingley, UK, pp 195-215

Cook CDK, Urmi-König K (1985) A revision of the genus Elodea (Hydrocharitaceae). Aquat Bot 21:111-156

Crall AW, Jordan R, Holfelder K et al (2012) The impacts of an invasive species citizen science training program on participant attitudes, behavior, and science literacy. Public Underst Sci. https://doi.org/10.1177/0963662511434894

Daniels MK, Iacona GD, Armsworth PR, Larson ER (2019) Do roads or streams explain plant invasions in forested protected areas? Biol Invasions 21(10):3121-3134

DCCED (2015) Alaska department of commerce, community, and economic development: division of corporations, business and professional licensing. https://www. commerce.alaska.gov/cbp/businesslicense/search/License. Accessed 22 Apr 2020

Dillman DA (2007) Mail and internet surveys: the tailored design method, 2nd edn. John Wiley \& Sons Inc, Hoboken, $\mathrm{NJ}$

Douma JC, Pautasso M, Venette RC et al (2016) Pathway models for analysing and managing the introduction of alien plant pests: an overview and categorization. Ecol Model 339:58-67

Encarnação J, Teodósio MA, Morais P (2021) Citizen science and biological invasions: a review. Front Environ Sci 8:303. https://doi.org/10.3389/fenvs.2020.602980

Evans C, Abrams E, Reitsma R et al (2005) The neighborhood nestwatch program: participant outcomes of a citizen-science ecological research project. Conserv Biol 19:589-594. https://doi.org/10.1111/j.1523-1739.2005. 00s01.x

FAA (2015) Airmen Certification Database. Federal Aviation Administration, Washington. https://www.faa.gov/ licenses_certificates/airmen_certification/releasable_ airmen_download/

FAA (2016) Flight operations count at Lake Hood in 2015. Federal Aviation Administration, Contact: Mark T. Collins, Renton, WA

FCC (2012) Internet Access services: status as of June 30, 2011. Federal Communications Commission Industry Analysis and Technology Division Wireline Competition Bureau, Washington, DC

FlyAlaska (2015) Alaska air charter companies, Alaska flight operations, Alaska air taxi companies. https://www. flyalaska.com/directoryp.html. Accessed from $22 \mathrm{Apr}$ 2020

Gabry J, Simpson D, Vehtari A et al (2019) Visualization in Bayesian workflow. J R Stat Soc A Stat Soc 182:389-402

Gaulke S, Martelli E, Johnson L et al (2019) Threatened and endangered mammals of Chile: does research align with conservation information needs? Conserv Sci Pract 1:e99. https://doi.org/10.1111/csp2.99

Gelman A, Rubin DB (1992) Inference from iterative simulation using multiple sequences. Stat Sci 7:457-472. https://doi. org/10.1214/ss/1177011136 
Gelman A, Carlin JB, Stern HS et al (2013) Bayesian data analysis. Chapman \& Hall/CRC, New York

Goodrich B, Gabry J, Ali I, Brilleman S (2020) rstanarm: Bayesian applied regression modeling via Stan. Version $\mathrm{R}$ package version 2.21.1 http://mc-stan.org/rstanarm

Haklay M (2013) Citizen science and volunteered geographic information: overview and typology of participation. In: Sui D, Elwood S, Goodchild M (eds) Crowdsourcing geographic knowledge: volunteered geographic information (VGI) in theory and practice. Springer, Netherlands, Dordrecht, pp 105-122

Hollander Z (2014) Lake-choking invasive weed makes it to Mat-Su. Anchorage Daily News

Hollander Z (2015) Pilots push for weed killer to combat Lake Hood's plane-fouling plants. Anchorage Daily News. https://www.adn.com/aviation/article/pilots-push-weedkiller-combat-lake-hood-s-plane-fouling-plants/2015/07/ 11/. Accessed 15 Dec 2021

Hudson H (2015) Connecting Alaskans. The University of Chicago Press, Chicago, IL

Huntington HP, Danielson SL, Wiese FK et al (2020) Evidence suggests potential transformation of the Pacific Arctic ecosystem is underway. Nat Clim Change 10(4):342-348

Johnson LE, Ricciardi A, Carlton JT (2001) Overland dispersal of aquatic invasive species: a risk assessment of transient recreational boating. Ecol Appl 11:1789. https://doi.org/ $10.2307 / 3061096$

Jordan RC, Gray SA, Howe DV et al (2011) Knowledge gain and behavioral change in citizen-science programs. Conserv Biol 25:1148-1154. https://doi.org/10.1111/j.15231739.2011.01745.x

Kelly NE, Wantola K, Weisz E, Yan ND (2013) Recreational boats as a vector of secondary spread for aquatic invasive species and native crustacean zooplankton. Biol Invasions 15:509-519. https://doi.org/10.1007/s10530-012-0303-0

Kent A, Drezner TD, Bello R (2018) Climate warming and the arrival of potentially invasive species into boreal forest and tundra in the Hudson Bay Lowlands, Canada. Polar Biol 41:2007-2022. https://doi.org/10.1007/s00300-018-23412

King R, Morgan B, Gimenez O, Brooks S (2009) Bayesian analysis for population ecology. Chapman and Hall/CRC, Florida

Lavrakas PJ (2008) Mixed-mode. Encyclopedia of survey research methods. Sage Publishing, California

Leung B, Mandrak NE (2007) The risk of establishment of aquatic invasive species: joining invasibility and propagule pressure. Proc Biol Sci R Soc 274:2603-2609. https://doi. org/10.1098/rspb.2007.0841

Leung B, Steele RJ (2013) The value of a datum - how little data do we need for a quantitative risk analysis? Divers Distrib 19:617-628. https://doi.org/10.1111/ddi.12062

Leung B, Bossenbroek JM, Lodge DM (2006) Boats, pathways, and aquatic biological invasions: estimating dispersal potential with gravity models. Biol Invasions 8:241-254. https://doi.org/10.1007/s10530-004-5573-8

Liedtke R, Barros A, Essl F et al (2020) Hiking trails as conduits for the spread of non-native species in mountain areas. Biol Invasions 22:1121-1134. https://doi.org/10.1007/s10530019-02165-9
Liu S, Walshe T, Long G, Cook D (2012) Evaluation of potential responses to invasive non-native species with structured decision making. Conserv Biol 26:539-546

Luizza MW, Evangelista PH, Jarnevich CS et al (2016) Integrating subsistence practice and species distribution modeling: assessing invasive elodea's potential impact on Native Alaskan subsistence of Chinook salmon and whitefish. Environ Manage 58:144-163

Marco DE, Montemurro MA, Cannas SA (2011) Comparing short and long-distance dispersal: modelling and field case studies. Ecography 34:671-682. https://doi.org/10.1111/j. 1600-0587.2010.06477.x

McGeoch MA, Genovesi P, Bellingham PJ et al (2016) Prioritizing species, pathways, and sites to achieve conservation targets for biological invasion. Biol Invasions 18:299-314. https://doi.org/10.1007/s10530-015-1013-1

McKinley DC, Miller-Rushing AJ, Ballard HL et al (2017) Citizen science can improve conservation science, natural resource management, and environmental protection. Biol Conserv 208:15-28. https://doi.org/10.1016/j.biocon. 2016.05.015

Morton JM, Blackburn BN, Bella E et al (2014) Integrated pest management plan for eradicating elodea from the Kenai Peninsula. Kenai Pensinsula Cooperative Weed Management Area, Kenai, Alaska

Muirhead JR, Bobeldyk AM, Bossenbroek JM et al (2009) Estimating dispersal and predicting spread on nonindigenous species. In: Keller RP, Lodge DM, Lewis MA, Shogren JF (eds) Bioeconomics of invasive species: integrating ecology, economics, policy, and management. Oxford University Press, New York, p 298

Panetta FD, Gooden B (2017) Managing for biodiversity: impact and action thresholds for invasive plants in natural ecosystems. NeoBiota 34:53-66

Prato T (2005) Bayesian adaptive management of ecosystems. Ecol Model 183:147-156. https://doi.org/10.1016/j. ecolmodel.2004.07.024

Professional Fisheries Consultants (1985) Eyak Lake AMSA cooperative management plan conceptually approved. https://copperriver.org/wp-content/uploads/2016/03/ AMSA-Cooperative-Report.pdf. Accessed 15 Dec 2021

Qualtrics (2021) Qualtrics survey platform. Qualtrics Software Company, Seattle

Runghen R, Mora BB, Godoy-Lorite A, Stouffer DB (2021) Assessing unintended human-mediated dispersal using visitation networks. J Appl Ecol 58:777-788. https://doi. org/10.1111/1365-2664.13829

Schmidt JI, Schwoerer T (2020) Alaska waterbodies“ fetch distance and elevation, 2015. Arctic Data Center. https:// doi.org/10.18739/A29S1KM2B

Schultz R, Dibble E (2012) Effects of invasive macrophytes on freshwater fish and macroinvertebrate communities: the role of invasive plant traits. Hydrobiologia 684:1-14. https://doi.org/10.1007/s10750-011-0978-8

Schwoerer T (2020) A survey of 2015 Alaska seaplane operations with predictions of transmission risk for aquatic invasive plants. https://doi.org/10.18739/A2N29P76G

Schwoerer T, Morton JM (2018) Human dimensions of aquatic invasive species in alaska: lessons learned while integrating economics, management, and biology to incentivize early detection and rapid response. In: Lewis $\mathrm{T}$ (ed) 
Alaska: economic, environmental, and social issues. Nova Science Publishers Inc, New York City, pp 1-46

Schwoerer T, Little JM, Schmidt JI, Borash KW (2020) Hitchhikers on floats to Arctic freshwater: private aviation and recreation loss from aquatic invasion. Ambio 49:1364-1376. https://doi.org/10.1007/s13280-01901295-7

Schwoerer T, Spellman KV, Davis TJ et al (2021) Harnessing the power of community science to address data gaps for Arctic observing: invasive species in Alaska as case examples. Arctic 74:1-14. https://doi.org/10.14430/ arctic73773

Sethi SA, Carey MP, Morton JM et al (2017) Rapid response for invasive waterweeds at the arctic invasion front: assessment of collateral impacts from herbicide treatments. Biol Conserv 212:300-309. https://doi.org/10.1016/j.biocon. 2017.06.015

Stanaway MA, Reeves R, Mengersen KL (2011) Hierarchical Bayesian modelling of plant pest invasions with humanmediated dispersal. Ecol Model 222:3531-3540. https:// doi.org/10.1016/j.ecolmodel.2011.08.013

Sytsma MD, Pennington T (2015) Vectors for spread of invasive freshwater vascular plants with a North American analysis.
In: Canning-Clode $\mathrm{J}$ (ed) Biological invasions in changing ecosystems vectors, ecological impacts, management and predictions. Walter de Gruyter GmbH \& Co KG, Berlin, pp 55-74

Tamayo M, Olden JD (2014) Forecasting the vulnerability of lakes to aquatic plant invasions. Invasive Plant Sci Manag 7:32-45. https://doi.org/10.1614/IPSM-D-13-00036.1

U.S. Census Bureau (2010) 2010 Census of Population and Housing. U.S Department of Commerce, Washington

USGS (2017) National hydrography dataset. http://nhd.usgs. gov/data.html. Accessed 31 Aug 2017

Vehtari A, Gelman A, Gabry J (2017) Practical bayesian model evaluation using leave-one-out cross-validation and WAIC. Stat Comput 27:1413-1432

von der Lippe M, Kowarik I (2007) Long-distance dispersal of plants by vehicles as a driver of plant invasions. Conserv Biol 21:986-996

Publisher's Note Springer Nature remains neutral with regard to jurisdictional claims in published maps and institutional affiliations. 